\title{
Intervensi Berbasis Digital Efektif Meningkatkan Kemampuan Matematika pada Siswa: Studi Metaanalisis
}

\section{Cynthia Vivian Purwanto, Ananta Yudiarso}

Program Studi Psikologi, Fakultas Psikologi, Universitas Surabaya, Surabaya

Abstrak. Numerasi merupakan salah satu jenis kemampuan yang penting bagi individu. Namun, tidak semua siswa memiliki numerasi yang memadai, sehingga dibutuhkan sebuah model intervensi yang dapat dengan efektif meningkatkan kemampuan matematika siswa. Adanya penggunaan teknologi yang semakin marak digunakan dalam dunia pendidikan telah memberikan terobosan untuk melakukan intervensi berbasis digital dalam mempelajari pelajaran matematika. Penelitian ini bertujuan untuk tinjauan literatur yang mengukur efektivitas dari penggunaan intervensi berbasis digital untuk meningkatkan kemampuan matematika. Metaanalisis dilakukan pada 18 jurnal penelitian yang terbit dalam 10 tahun terakhir dengan 1,721 responden di kelompok eksperimen dan 1,219 responden di kelompok kontrol yang relevan dengan penelitan ini. Berdasarkan uji perbedaan mean $(M, S D$, dan $n)$, ditemukan nilai dari effect size adalah sebesar $g$ $=.492\left(95 \% \mathrm{CI}=[.287, .706] ; p<.001 ; \mathrm{I}^{2}\right.$ (inconsistency) $\left.=84.43 \%\right)$. Hasil ini menunjukkan nilai effect size yang diperoleh mirip dengan penelitian dari Benavides-Varela et al. (2020) yang menemukan bahwa intervensi berbasis digital efektif untuk meningkatkan kemampuan matematika pada siswa diskalkulia. Tingkat pendidikan sebagai moderator juga terbukti tidak mempengaruhi penggunaan media digital untuk meningkatkan kemampuan matematika yang dimiliki siswa ( $p=.359)$. Nilai effect size yang diperoleh apabila menggunakan tingkat pendidikan sebagai moderator adalah $g=.398\left(95 \% \mathrm{CI}=[-.483, .175] ; p<.001 ; \mathrm{I}^{2}(\right.$ inconsistency $\left.)=84.02 \%\right)$. Oleh karena itu, pendidik dapat menggunakan media digital sebagai salah satu alat yang menunjang pembelajaran matematika siswa, baik di tingkat prasekolah hingga perguruan tinggi.

Kata Kunci: intervensi berbasis digital, kemampuan matematika, metaanalisis

\section{Digital-Based Interventions are Effective in Improving Mathematics Skill for Students: A Meta-Analysis Study}

Abstract. Numeracy is one of the most necessary skills needed. However, not every student has sufficient numeracy, therefore it is needed an effective intervention to improve students' mathematics skill. The widely use of technology in education has provided a breakthrough for conducting digital-based interventions in learning mathematics. This study goal is to review the literature which measures the effectiveness of digital-based intervention to improve mathematics skill. Meta-analysis done to eighteen journals published in the past decade with 1,721 participants of experiment group and 1,219 participants of control groups which are relevant to this study. Based on mean differences $(M, S D$, and $n)$ analysis, it is found that the effect size was $g=.492\left(95 \% \mathrm{CI}=[.287, .706] ; p<.001 ; \mathrm{I}^{2}\right.$ (inconsistency) $\left.=84.43 \%\right)$. This shows that the effect size obtained is similar to Benavides-Varela et al. (2020) study which found digital-based interventions are effective to improve dyscalculia students' mathematics skill. There is also no evidence which shows level of education affects the use of digital intervention to improve students' mathematics skill $(p=.359)$. The effect size obtained while using level of education as moderator is $g=.398\left(95 \% \mathrm{CI}=[-.483, .175] ; p<.001 ; \mathrm{I}^{2}\right.$ (inconsistency) $=84.02 \%$ ). Therefore, educators can use digital media as a tool to support students' mathematics learning, both at the preschool to college level.

Keywords: digital-based intervention, mathematics skills, meta-analysis

Korespondensi: Cynthia Vivian Purwanto. Email: ceve.cv@gmail.com 
Salah satu kemampuan yang penting menjadi kompetensi individu adalah numerasi. Hal ini dikarenakan numerasi berperan penting pada kehidupan individu (De Lange, 2003; Haelermans \& Ghysels, 2017), tetapi tidak semua individu memiliki numerasi yang baik (Haelermans \& Ghysels, 2017). Numerasi dapat dipelajari melalui pelajaran matematika di sekolah. Penelitian PISA yang dilakukan oleh OECD (Hillmayr et al., 2020) menunjukkan bahwa terdapat banyak siswa yang mengalami kendala ketika mempelajari matematika. Banyak faktor yang menyebabkan siswa mengalami kendala tersebut, salah satunya adalah karena adanya rasa bosan yang dialami siswa (Baki \& Güveli, 2008) dan rasa takut belajar matematika (Aliasgari et al, 2010). Oleh karena itu, perlu adanya penanganan tertentu yang dapat membantu individu, terutama siswa di sekolah agar dapat dengan mudah mempelajari pelajaran matematika.

Adanya keuntungan dalam penggunaan teknologi membuat adanya perubahan serta inovasi dalam dunia pendidikan (Özyurt et al,, 2014). Hal ini menyebabkan penggunaan teknologi digital juga semakin marak digunakan dalam dunia pendidikan. Banyak guru yang menggunakan media teknologi dalam mengajar (Pilli \& Aksu, 2013), terutama ketika dunia sedang dilanda wabah COVID-19 yang terjadi sejak akhir Desember 2019. Proses belajarmengajar tetap harus berjalan, tetapi guru maupun siswa harus berdiam diri di rumah. Tentunya peran media teknologi sangat besar dalam memudahkan proses belajar tersebut. Keuntungan lain dari penggunaan teknologi dalam proses belajar siswa adalah adanya kesempatan belajar yang lebih besar bagi siswa (Shadaan \& Leong, 2013) karena siswa dapat belajar tidak terbatas oleh tempat dan waktu (van der Ven et al., 2017), meningkatkan keterlibatan siswa (Shadaan \& Leong, 2013; van der Ven et al., 2017), mendorong adanya penemuan (Shadaan \& Leong, 2013), dan meningkatkan motivasi dan kepercayaan diri siswa (Zulnaidi \& Zakaria, 2012).

Adanya kombinasi dari penggunaan media digital dan kurangnya kemampuan matematika siswa telah memberikan terobosan dalam ragam intervensi yang dilakukan, yaitu intervensi berbasis digital untuk meningkatkan kemampuan matematika (Haelermans \& Ghysels, 2017). Inovasi tersebut dapat berupa pengembangan alat, seperti interactive whiteboards (Tunaboylu \& Demir, 2016), Geometers Sketchpad (Shadaan \& Leong, 2013), dan GeoGebra (Saha et al., 2010; Shadaan \& Leong, 2013; Zengin et al., 2012; Zulnaidi \& Zakaria, 2012) maupun pengembangan kurikulum atau metode berbasis teknologi, seperti Computer-assisted instruction (CAI) (Aliasgari et al, 2010; Pilli \& Aksu, 2013), mobile learning (Fabian \& Topping, 2019), individualized digital practice (Haelermans \& Ghysels, 2017), SimCalc (Hegedus et al, 2015; Roschelle et al, 2010), UZWEBMAT (Özyurt et al., 2014), Math Shelf (Schacter \& Jo, 2016), WebQuest (Yenmez et al., 2017) atau Cabri. 
Inovasi yang dilakukan juga berupa pengembangan permainan digital pada komputer maupun tablet (Pitchford, 2015; van der Ven et al., 2017) atau berupa Action Video Games (AVG) (Novak \& Tassell, 2015).

Jika mengajar matematika menggunakan metode konvensional, yaitu dengan menggunakan contoh yang abstrak (Pilli \& Aksu, 2013), maka dengan bantuan teknologi, pemberian contoh dapat dengan langsung dilakukan simulasi pada siswa (Pilli \& Aksu, 2013). Hal ini tentunya dapat memudahkan siswa untuk memahami suatu konsep matematika. Penggunaan teknologi, salah satunya melalui software, dapat menyediakan peluang bagi siswa untuk berlatih dan mendapatkan umpan balik yang cepat melalui lingkungan yang memotivasi serta mampu meningkatkan cara berpikir pada tingkat yang lebih tinggi (Roschelle et al., 2010).

Terdapat beberapa penelitian yang melakukan penelitian efektivitas penggunaan teknologi digital dalam ranah pendidikan (Hillmayr et al, 2020). Namun, masih timbul perdebatan mengenai efektivitas intervensi berbasis digital di ranah pendidikan, termasuk pada pelajaran matematika (Benavides-Varela et al., 2020; Hillmayr et al., 2020). Sebagai contoh, penelitian dari Aliasgari et al (2010); Fabian \& Topping (2019); Haelermans \& Ghysels (2017); Hegedus et al (2015); Novak \& Tassell (2015); Özyurt et al (2014); Pilli \& Aksu (2013); Pitchford (2015); Roschelle et al (2010); Saha et al (2010); Schacter \& Jo (2016);
Shadaan \& Leong (2013); Tunaboylu \& Demir (2016); van der Ven et al (2017); Yenmez et al (2017); Zengin et al (2012); Zulnaidi \& Zakaria (2012) menunjukkan adanya keefektifan dalam penggunaan media digital untuk meningkatkan berbagai macam kemampuan matematika siswa. Sebaliknya, penelitian milik Perry \& Steck (2015) menunjukkan bahwa penggunaan iPad sebagai media pembelajaran geometri dinilai kurang efektif dalam peningkatan kemampuan geometri siswa.

Penelitian metaanalisis terkait efektivitas media digital terhadap prestasi matematika siswa juga pernah dilakukan. metaanalisis dari Byun \& Joung (2018) menunjukkan bahwa pembelajaran menggunakan permainan digital mampu meningkatkan prestasi siswa di bidang matematika. Penelitian Tokac et al (2019) secara lebih spesifik menemukan bahwa pembelajaran menggunakan video game berperan dalam meningkatkan kemampuan matematika siswa. Metaanalisis yang dilakukan oleh Benavides-Varela et al (2020) juga menunjukkan nilai effect-size yang memadai untuk membuktikan bahwa teknologi berbasis digital dapat menjadi intervensi yang tepat untuk meningkatkan kompetensi matematika siswa. Penelitian (Benavides-Varela et al., 2020) ini lebih memfokuskan pada responden penelitian siswa yang mengalami diskalkulia, sedangkan untuk penelitian metaanalisis serupa yang menggunakan responden siswa yang tidak mengalami diskalkulia belum dilakukan. 
Oleh karena itu, penelitian metaanalisis ini dilakukan untuk mengetahui efektivitas dari intervensi teknologi berbasis digital terhadap kemampuan matematika siswa. Penelitian ini menggunakan tingkat pendidikan sebagai moderator dalam melihat keefektifan dari penggunaan intervensi teknologi berbasis digital untuk meningkatkan kemampuan matematika siswa. Pada penelitian Tokac et al (2019) mengungkapkan bahwa tingkat pendidikan yang semakin tinggi memiliki tingkat kesulitan dalam pelajaran matematika yang semakin tinggi pula dan juga berhubungan dengan semakin menurunnya motivasi siswa dalam belajar, sehingga diduga keefektifan penggunaan media digital sebagai intervensi terhadap kemampuan matematika siswa dari berbagai tingkat pendidikan juga bervariasi. Tingkat pendidikan juga diprediksi mempengaruhi kemampuan penggunaan media digital siswa yang dapat berpengaruh terhadap keefektifan intervensi.

\section{Metode}

\section{Prosedur penelitian}

Pencarian penelitian dilakukan pada di Science Direct dan Springer Link dengan kata kunci "digital intervention for mathematics" dan "technology intervention for mathematics". Penelitian dibatasi pada penelitian yang dipublikasikan di jurnal internasional pada sepuluh tahun terakhir, yaitu 2010 hingga 2020. Penelitian yang dipilih juga merupakan penelitian eksperimen yang menggunakan kelompok kontrol dan eksperimen serta melampirkan jumlah sampel ( $n$ ), $M$, dan $S D$ dari masing-masing kelompok. Skema penelusuran penelitian terdahulu terlampir pada Gambar 1. Setelah melewati seleksi terhadap kesesuaian kriteria, diperoleh delapan belas jurnal yang memenuhi kriteria penelitian.

\section{Gambar 1}

\section{Skema Penelusuran Penelitian Terdahulu}

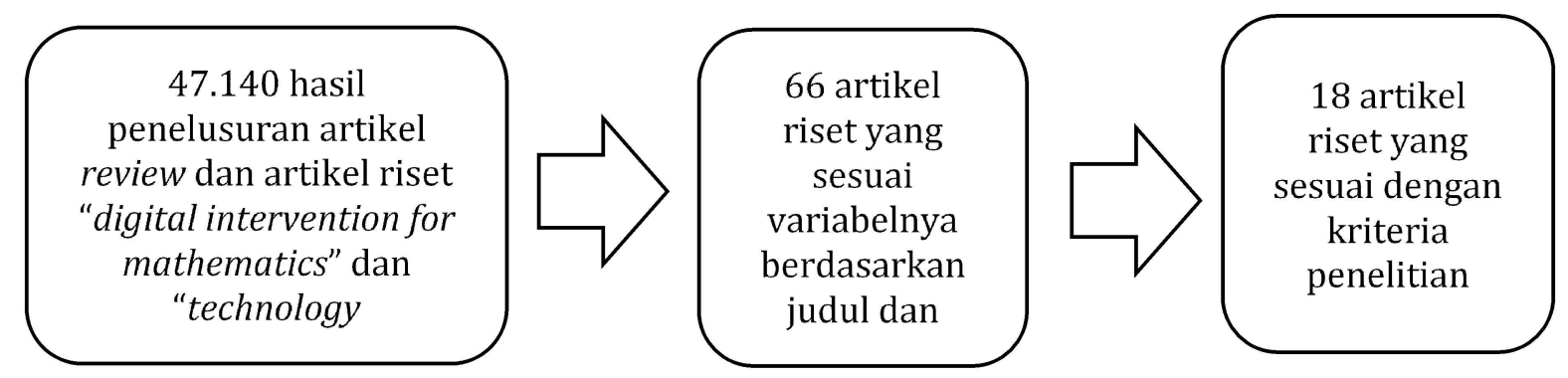

\section{Analisis data}

Metaanalisis dilakukan dengan menggunakan software Jamovi 1.6.6 (Jamovi, 2020) dengan melihat effect size dari delapan belas penelitian terdahulu. Variabel moderator yang digunakan, yaitu tingkat pendidikan, dibagi menjadi empat kategori: prasekolah, sekolah dasar, sekolah menengah, dan perguruan tinggi. Effect size diperoleh dengan analisis mean difference berdasarkan jumlah 
sampel, nilai mean, serta nilai standar deviasi dari kedua kelompok. Hasil effect size dikatakan kecil, sedang, dan besar apabila nilai Hedges' $g$ berada pada batas minimal .15, .38, dan .69 (Brydges, 2019). Heterogenitas dari penelitian ini dilihat dari nilai $\mathrm{I}^{2}$, sedangkan bias penelitian dilihat dari nilai Egger.

\section{Hasil}

Metaanalisis ini memiliki besar heterogenitas sebesar $\mathrm{I}^{2}=84.43 \%$. Hal ini menunjukkan bahwa ada variasi yang besar pada penelitian-penelitian terdahulu, sehingga effect model yang digunakan untuk melihat besar effect size adalah random effect model. Penelitian ini juga tidak menunjukkan adanya bias publikasi karena nilai Bias Egger yang diperoleh adalah $p=.258$. Nilai $p$ dari Bias Egger yang besar ini menunjukkan bahwa tidak ditemukan perbedaan pada penelitianpenelitian terdahulu yang dapat menimbulkan bias publikasi, sehingga studi metaanalisis ini layak untuk dianalisis lebih lanjut.

Subjek dari penelitian ini adalah 2,940 siswa, dengan rincian 1,721 siswa di kelompok eksperimen dan 1,219 siswa di kelompok kontrol. Responden terdiri dari siswa sekolah dasar, menengah dan perguruan tinggi. Rincian dari masing-masing penelitian terlampir pada Tabel 1. Hasil dari analisis mean difference terhadap delapan belas penelitian menunjukkan nilai effect size yang sedang mengarah ke besar, yaitu sebesar $g=.492(95 \% \mathrm{CI}=[.278, .706] ; p$ $<.001$ ) dengan nilai Z sebesar 4.51. Berdasarkan forest plot yang terlampir pada Gambar 2, effect size terkecil ditunjukkan pada penelitian milik Pitchford (2015), yaitu sebesar $g=.13$ (95\% CI $=-.47-.74$ ) dan effect size terbesar ditunjukkan pada penelitian milik Zengin et al (2012), yaitu sebesar $g=1.61(95 \% \mathrm{CI}=[.97,2.24])$. Terdapat satu penelitian yang memiliki nilai effect size negatif, yaitu penelitian dari Perry \& Steck (2015), yang berarti intervensi yang dilakukan justru memberikan efek yang terbalik pada kemampuan matematika siswa. Apabila menggunakan moderator, nilai effect size yang diperoleh juga tergolong sedang, yaitu sebesar $g=.398(95 \% \mathrm{CI}=[-.483, .175] ; p<.001)$ dengan nilai $\mathrm{I}^{2}=84.02 \%, \mathrm{Z}=-.918$, dan $p$ dari moderator sebesar.359. 
Tabel 1

Rincian Penelitian Intervensi Berbasis Digital pada Kemampuan Matematika

\begin{tabular}{|c|c|c|c|c|c|c|}
\hline Penelitian & Variabel & Intervensi KE & $\begin{array}{c}\text { Intervensi } \\
\mathrm{KK}\end{array}$ & $\begin{array}{c}\text { Tingkat } \\
\text { Pendidikan }\end{array}$ & $g$ & $95 \% \mathrm{CI}$ \\
\hline Aliasgari et al (2010) & Combinatory analysis \& probability & $\begin{array}{l}\text { Computer- assisted } \\
\text { instruction (CAI) }\end{array}$ & Tradisional & $\begin{array}{l}\text { Sekolah } \\
\text { menengah }\end{array}$ & .95 & {$[.36,1.54]$} \\
\hline $\begin{array}{l}\text { Fabian \& Topping } \\
\text { (2019) }\end{array}$ & $\begin{array}{l}\text { Symmetry, angles and area \& } \\
\text { perimeter. }\end{array}$ & Mobile learning & Tradisional & Sekolah dasar & .16 & {$[-.30, .61]$} \\
\hline $\begin{array}{l}\text { Haelermans \& Ghysels } \\
\text { (2017) }\end{array}$ & Primary school ability test numeracy & $\begin{array}{l}\text { Individualized } \\
\text { digital practice }\end{array}$ & Tradisional & $\begin{array}{l}\text { Sekolah } \\
\text { menengah }\end{array}$ & .20 & {$[-.03, .43]$} \\
\hline Hegedus et al (2015) & Advance Algebra & SimCalc & Tradisional & $\begin{array}{l}\text { Sekolah } \\
\text { menengah }\end{array}$ & .35 & {$[.18, .52]$} \\
\hline Novak \& Tassell (2015) & Geometry, word \& non-word problems & $\begin{array}{l}\text { Action Video } \\
\text { Games (AVG) }\end{array}$ & Non-AVG & $\begin{array}{l}\text { Perguruan } \\
\text { tinggi }\end{array}$ & .18 & {$[-.54, .90]$} \\
\hline Özyurt et al (2014) & $\begin{array}{l}\text { secondary education } 8 \text { th grade and } \\
11 \text { th } \\
\text { grade mathematics curricula }\end{array}$ & UZWEBMAT & Tradisional & $\begin{array}{l}\text { Sekolah } \\
\text { menengah }\end{array}$ & .58 & {$[.19, .97]$} \\
\hline Perry \& Steck (2015) & geometry & iPad & Non-iPad & $\begin{array}{l}\text { Sekolah } \\
\text { menengah }\end{array}$ & -.62 & {$[-1.00,-.23]$} \\
\hline Pilli \& Aksu (2013) & $\begin{array}{l}\text { Multiplication } \\
\text { symbolic understanding, numbers in } \\
\text { relation to each other, number line } \\
\text { understanding, }\end{array}$ & CAI & Tradisional & Sekolah dasar & .62 & {$[.08,1.16]$} \\
\hline Pitchford (2015) & $\begin{array}{l}\text { counting, number sense (quantity } \\
\text { estimation), simple and complex } \\
\text { addition, simple and complex } \\
\text { subtraction, and multiplication and } \\
\text { division }\end{array}$ & Maths tablet & Tradisional & Sekolah dasar & .13 & {$[-.47, .74]$} \\
\hline Roschelle et al (2010) & $\begin{array}{l}\text { Rate and proportionality, linear } \\
\text { function }\end{array}$ & SimCalc & Tradisional & $\begin{array}{l}\text { Sekolah } \\
\text { menengah }\end{array}$ & .41 & {$[.26, .55]$} \\
\hline Saha et al (2010) & Coordinate Geometry & GeoGebra & Tradisional & $\begin{array}{l}\text { Sekolah } \\
\text { menengah }\end{array}$ & .59 & {$[.04,1.14]$} \\
\hline Schacter \& Jo (2016) & $\begin{array}{l}\text { Quantity discrimination, numeral } \\
\text { identification, numeral sequence, } \\
\text { cardinal principle, comparing } \\
\text { quantities, matching numerals to } \\
\text { quantities }\end{array}$ & Math Shelf & Tradisional & Prasekolah & 1.05 & {$[.73,1.38]$} \\
\hline $\begin{array}{l}\text { Shadaan \& Leong } \\
\text { (2013) }\end{array}$ & Circles & GeoGebra & Tradisional & $\begin{array}{l}\text { Sekolah } \\
\text { menengah }\end{array}$ & 1.08 & {$[.50,1.66]$} \\
\hline Tunaboylu \& Demir & Equation and Equality & $\begin{array}{l}\text { Interactive } \\
\text { whiteboards } \\
\text { teaching }\end{array}$ & Tradisional & $\begin{array}{l}\text { Sekolah } \\
\text { menengah }\end{array}$ & .67 & {$[.14,1.20]$} \\
\hline $\begin{array}{l}\text { van der Ven et al } \\
\text { (2017) }\end{array}$ & $\begin{array}{l}\text { Arabic-addition, Arabic-subtraction, } \\
\text { dot-addition, dot-subtraction problems. }\end{array}$ & Tablet game & Tradisional & Sekolah dasar & .64 & {$[.25,1.04]$} \\
\hline Yenmez et al (2017) & Data, counting and probability & WebQuests & $\begin{array}{l}\text { Tidak ada } \\
\text { intervensi }\end{array}$ & $\begin{array}{l}\text { Sekolah } \\
\text { menengah }\end{array}$ & .20 & {$[-.25, .64]$} \\
\hline Zengin et al (2012) & Trigonometry & GeoGebra & Tradisional & $\begin{array}{l}\text { Sekolah } \\
\text { menengah }\end{array}$ & 1.61 & {$[.97,2.24]$} \\
\hline $\begin{array}{l}\text { Zulnaidi \& Zakaria } \\
\text { (2012) }\end{array}$ & $\begin{array}{l}\text { conceptual and procedural knowledge } \\
\text { of mathematics }\end{array}$ & GeoGebra & Tradisional & $\begin{array}{l}\text { Sekolah } \\
\text { menengah }\end{array}$ & .42 & {$[.07, .78]$} \\
\hline
\end{tabular}

Catatan. $g$ = Hedge effect size; $\mathrm{CI}=$ confidence interval; $\mathrm{KE}=$ Kelompok Eksperimen; $\mathrm{KK}=$ Kelompok Kontrol 


\section{Gambar 2}

Forest Plot

\begin{tabular}{|c|c|c|c|}
\hline Novak (2015) & $\longmapsto$ & \multirow{3}{*}{$\rightleftarrows$} & $0.18[-0.54,0.90]$ \\
\hline Aliasgari (2010) & \multirow{17}{*}{$\longmapsto$} & & $0.95[0.36,1.54]$ \\
\hline Haelermans (2017) & & & $0.20[-0.03,0.43]$ \\
\hline Hegedus (2015) & & $r$ & $0.35[0.18,0.52]$ \\
\hline Ozyurt (2014) & & $\longmapsto$ & $0.58[0.19,0.97]$ \\
\hline Perry (2015) & & $\infty$ & $-0.62[-1.00,-0.23]$ \\
\hline Roschelle (2010) & & $+r$ & $0.41[0.26,0.55]$ \\
\hline Saha (2010) & & $\longmapsto$ & $0.59[0.04,1.14]$ \\
\hline Shadaan (2013) & & $\longmapsto$ & $1.08[0.50,1.66]$ \\
\hline Tunaboylu (2017) & & $\longmapsto$ & $0.67[0.14,1.20]$ \\
\hline Yenmez (2017) & & $\rightarrow$ & $0.20[-0.25,0.64]$ \\
\hline Zengin (2012) & & $\longrightarrow \longmapsto$ & $1.61[0.97,2.24]$ \\
\hline Zulnaidi (2012) & & $\longmapsto$ & $0.42[0.07,0.78]$ \\
\hline Fabian (2019) & & -1 & $0.16[-0.30,0.61]$ \\
\hline Pili (2013) & & $\longmapsto$ & $0.62[0.08,1.16]$ \\
\hline Pitchford (2015) & & $\longrightarrow$ & $0.13[-0.47,0.74]$ \\
\hline van der Ven (2017) & & $\longmapsto$ & $0.64[0.25,1.04]$ \\
\hline Schacter (2016) & & $\longmapsto$ & $1.05[0.73,1.38]$ \\
\hline & 1 & $T$ & \\
\hline-2 & -1 & 2 & \\
\hline
\end{tabular}

\section{Pembahasan}

Perkembangan media digital yang semakin pesat merupakan salah satu hal yang menjanjikan dalam memberikan efek positif pada pendidikan siswa, salah satunya dalam pelajaran matematika. Hal ini menyebabkan keefektivitasan intervensi berbasis digital pada kemampuan matematika siswa menjadi salah satu pertanyaan utama bagi pendidik, orang tua, maupun pihak lain yang ingin menggunakan media digital dalam meningkatkan kemampuan matematika siswa. Hasil metaanalisis ini menunjukkan bahwa effect size yang diperoleh adalah sedang ke besar (medium to large). Menurut Bakker et al (2019), dalam menilai hasil metaanalisis, penilaian sebaiknya dilakukan dengan membandingkan dengan penelitian terdahulu yang serupa. Hasil dari penelitian ini serupa dengan hasil metaanalisis yang dilakukan oleh Benavides-Varela et al (2020) yang menyatakan bahwa intervensi berbasis media digital efektif dalam meningkatkan kemampuan matematika pada anak yang mengalami mathematical learning difficulties (MLD). Penemuan ini menunjukkan bahwa intervensi berbasis digital efektif dalam meningkatkan kemampuan matematika siswa. Hasil ini juga sejalan dengan penelitian metaanalisis dari Byun \& Joung (2018) yang meneliti penggunaan permainan digital serta Tokac et al (2019) yang meneliti penggunaan video games dalam meningkatkan kemampuan matematika. 
Hasil penelitian ini menunjukkan semua penelitian terdahulu memiliki nilai effect size positif, kecuali pada penelitian dari Perry \& Steck (2015). Pada penelitian tersebut ketidakefektifan dari penggunaan iPad diduga timbul karena penggunaan iPad masih baru dan belum akrab bagi siswa, sehingga siswa membutuhkan waktu dan pendampingan dari guru untuk menggunakan iPad (Perry \& Steck, 2015). Distraksi dari penggunaan media digital juga diduga menjadi penyebab kurang efektifnya penggunaan iPad sebagai intervensi (Perry \& Steck, 2015). Pendampingan oleh guru dapat menjadi cara untuk meminimalisir adanya distraksi dari penggunaan media digital. Dukungan berupa pendampingan oleh guru juga merupakan salah satu kebutuhan psikologis dasar yang dibutuhkan oleh siswa (Yu \& Singh, 2018). Pemenuhan dukungan oleh guru tersebut menyebabkan siswa menjadi lebih tertarik dan menikmati kegiatan pembelajaran, lebih yakin terhadap mata pelajaran tersebut, ingin lebih berhasil, dan menjadi lebih termotivasi (Yu \& Singh, 2018). Siswa juga menjadi lebih memiliki tujuan, berani meminta bantuan, dapat meregulasi diri, serta lebih terlibat dalam penugasan dan pembelajaran ketika mendapatkan dukungan guru (Yu \& Singh, 2018). Pendampingan langsung oleh guru ini diduga membuat efektivitas intervensi berbasis digital menjadi lebih efektif karena siswa termotivasi, yakin terhadap kemampuannya, dan mengakibatkan keterlibatan lebih pada proses pembelajaran.
Keterlibatan yang lebih ini nantinya membuat siswa menjadi lebih mampu mendapatkan prestasi yang lebih baik (Yu \& Singh, 2018).

Analisis lebih lanjut dilakukan dengan menggunakan tingkat pendidikan sebagai moderator. Tingkat pendidikan diprediksi berkontribusi terhadap penguasaan digital yang dapat mempengaruhi keefektifannya dalam meningkatkan kemampuan matematika siswa. Hasil yang diperoleh menunjukkan bahwa tingkat pendidikan tidak berpengaruh terhadap keefektifan dari intervensi berbasis digital yang dilakukan. Hal ini dapat terjadi karena berdasarkan penelitian dari Pérez-Escoda et al (2016), ditemukan bahwa kemampuan penggunaan media digital tidak dipengaruhi oleh tingkat pendidikan. Karena tingkat pendidikan tidak mempengaruhi kemampuan penggunaan media digital, maka dapat disimpulkan bahwa intervensi berbasis digital cukup menjanjikan dalam upaya meningkatkan kemampuan matematika pada siswa prasekolah, sekolah dasar, sekolah menengah, maupun perguruan tinggi.

Implikasi dari penemuan ini adalah penggunaan intervensi ini dapat dilakukan sejak siswa duduk di prasekolah hingga perguruan tinggi. Terdapat keterbatasan dalam penelitian meta-analisis ini yang perlu diperhatikan. Pertama, penelitian ini memiliki nilai effect size yang sedang ke arah besar. Keefektifan dari penggunaan intervensi berbasis digital terhadap peningkatan kemampuan matematika siswa akan lebih meyakinkan apabila effect size yang 
dihasilkan besar. Kedua, variabel tingkat pendidikan sebagai moderator tidak berpengaruh terhadap effect size yang diperoleh. Perlu ditemukan variabel lain yang mempengaruhi efektivitas dari intervensi berbasis digital dalam meningkatkan kemampuan matematika, sehingga dapat dikontrol dalam penelitian selanjutnya.

\section{Simpulan}

Hasil dari metaanalisis terhadap 18 penelitian menunjukkan secara keseluruhan nilai effect size yang diperoleh adalah sedang mengarah ke besar dan serupa dengan penelitian sejenis (Benavides-Varela et al., 2020), sehingga dapat disimpulkan bahwa intervensi berbasis digital efektif dalam meningkatkan kemampuan matematika siswa. Berdasarkan hasil temuan ini, penggunaan pembelajaran berbasis digital dapat menjadi salah satu metode yang digunakan oleh pendidik atau pun orang tua dalam menunjang pembelajaran matematika siswa. Ditemukan pula bahwa tingkat pendidikan tidak memberikan pengaruh terhadap keefektifan penggunaan intervensi berbasi digital pada peningkatan kemampuan matematika.

\section{Saran}

Penelitian replikasi lebih lanjut layak untuk dilakukan dengan menambahkan penelitian sejenis untuk lebih meyakinkan hasil dari keefektifan penggunaan intervensi berbasis digital untuk meningkatkan kemampuan matematika siswa. Pada penelitian selanjutnya juga perlu menggunakan variabelvariabel pengontrol lain diduga dapat yang mempengaruhi efektivitas dari intervensi berbasis digital dalam meningkatkan kemampuan matematika, seperti pendampingan guru, jenis intervensi digital, dan jenis materi matematika.

\section{Referensi}

Aliasgari, M., Riahinia, N., \& Mojdehavar, F. (2010). Computer assisted instruction and student attitudes towards learning mathematics. Education, Business and Society: Contemporary Middle Eastern Issues, 3(1), 6-14. https://doi.org/ 10.1108/17537981011022779

Baki, A., \& Güveli, E. (2008). Evaluation of a web based mathematics teaching material on the subject of functions. Computers \& Education, 51(2), 854-863. h ttps://doi.org/10.1016/ j.compedu.2007.09.003

Bakker, A., Cai, J., English, L., Kaiser, G., Mesa, V., \& Van Dooren, W. (2019). Beyond small, medium, or large: points of consideration when interpreting effect sizes. Educational Studies in Mathematics, 102(1), 1-8. https://doi.org/10.1007/ s10649-019-09908-4

Benavides-Varela, S., Zandonella Callegher, C., Fagiolini, B., Leo, I., Altoè, G., \& Lucangeli, D. (2020). Effectiveness of digital-based interventions for children with mathematical learning difficulties: A meta-analysis. Computers \& Education, 157, 103953. https://doi.org/10.1016/ j.compedu.2020.103953

Brydges, C. R. (2019). Effect size guidelines, sample size calculations, and statistical power in gerontology. Innovation in Aging, 3(4), 1-8. https://doi.org/ 10.1093/geroni/igz036 
Byun, J., \& Joung, E. (2018). Digital game-based learning for K-12 mathematics education: A meta-analysis. School Science and Mathematics, 118(3-4), 113-126. https://doi.org/10.1111/ssm.12271

De Lange, J. (2003). "Mathematics for Literacy." In Madison, B.L. \& Steen, A (eds), Quantitative Literacy: Why Numeracy Matters for Schools and Colleges. National Council on Education and the Diciplines.

Fabian, K., \& Topping, K. J. (2019). Putting "mobile" into mathematics: Results of a randomised controlled trial. Contemporary Educational Psychology, 59, 101783. https://doi.org/10.1016/ j.cedpsych.2019.101783

Haelermans, C., \& Ghysels, J. (2017). The effect of individualized digital practice at home on math skills-Evidence from a twostage experiment on whether and why it works. Computers \& Education, 113, 119-134. https://doi.org/10.1016/ j.compedu.2017.05.010

Hegedus, S. J., Dalton, S., \& Tapper, J. R. (2015). The impact of technology-enhanced curriculum on learning advanced algebra in US high school classrooms. Educational Technology Research and Development, 63(2), 203-228. https:// doi.org/10.1007/s11423-015-9371-z

Hillmayr, D., Ziernwald, L., Reinhold, F., Hofer, S. I., \& Reiss, K. M. (2020). The potential of digital tools to enhance mathematics and science learning in secondary schools: A context-specific meta-analysis. Computers \& Education, 153, 103897. h ttps://doi.org/10.1016/ j.compedu.2020.103897

Jamovi. (2020). The jamovi project (1.6). https://www.jamovi.org.

Novak, E., \& Tassell, J. (2015). Using video game play to improve education-majors' mathematical performance: An experimental study. Computers in Human Behavior, 53, 124-130. https://doi.org/ 10.1016/j.chb.2015.07.001
Özyurt, Ö., Özyurt, H., Güven, B., \& Baki, A. (2014). The effects of UZWEBMAT on the probability unit achievement of Turkish eleventh grade students and the reasons for such effects. Computers \& Education, 75, 1-18. https://doi.org/10.1016/ j.compedu.2014.02.005

Pérez-Escoda, A., Castro-Zubizarreta, A., \& Fandos-Igado, M. (2016). Digital skills in the $\mathrm{Z}$ generation: Key questions for a curricular introduction in primary school. Comunicar, 24(49), 71-79. https://doi.org/10.3916/C49-2016-07

Perry, D. R., \& Steck, A. K. (2015). Increasing student engagement, self-efficacy, and meta-cognitive self-regulation in the high school geometry classroom: Do iPads help? Computers in the Schools, 32(2), 122-143. https://doi.org/10.1080/ 07380569.2015.1036650

Pilli, O., \& Aksu, M. (2013). The effects of computer-assisted instruction on the achievement, attitudes and retention of fourth grade mathematics students in North Cyprus. Computers \& Education, 62, 62-71. https://doi.org/10.1016/ j.compedu.2012.10.010

Pitchford, N. J. (2015). Development of early mathematical skills with a tablet intervention: A randomized control trial in Malawi. Frontiers in Psychology, 6. h ttps://doi.org / 10.3389 / fpsyg.2015.00485

Roschelle, J., Shechtman, N., Tatar, D., Hegedus, S., Hopkins, B., Empson, S., Knudsen, J., \& Gallagher, L. P. (2010). Integration of technology, curriculum, and professional development for advancing middle school mathematics. American Educational Research Journal, 47(4), 833-878. h ttp s: / / doi.org / 10.3102 / 0002831210367426

Saha, R. A., Ayub, A. F. M., \& Tarmizi, R. A. (2010). The effects of geoGebra on mathematics achievement: Enlightening coordinate geometry learning. Procedia - Social and Behavioral Sciences, 8, 686-693. https:/ /doi.org/10.1016/j.sbspro.2010.12.095 
Schacter, J., \& Jo, B. (2016). Improving lowincome preschoolers mathematics achievement with Math Shelf, a preschool tablet computer curriculum. Computers in Human Behavior, 55, 223$229 . \quad$ https://doi.org/10.1016/ j.chb.2015.09.013

Shadaan, P., \& Leong, K. E. (2013). Effectiveness of using GeoGebra on students' understanding in learning circles. The Malaysian Online Journal of Educational Technology, 1(4). https:// files.eric.ed.gov/fulltext/EJ1086434.pdf

Tokac, U., Novak, E., \& Thompson, C. G. (2019). Effects of game based learning on students' mathematics achievement: A meta analysis. Journal of Computer Assisted Learning, 35(3), 407-420. https:// doi.org/10.1111/jcal.12347

Tunaboylu, C., \& Demir, E. (2016). The effect of teaching supported by interactive whiteboard on students' mathematical achievements in lower secondary education. Journal of Education and Learning, 6(1), 81. https://doi.org/ $10.5539 /$ jel.v6n1p81

van derVen,F.,Segers, E., Takashima, A., \& Verhoeven, L. (2017). Effects of a tablet game intervention on simple addition and subtraction fluency in first graders. Computers in Human Behavior, 72, 200-207. https://doi.org/10.1016/ j.chb.2017.02.031
Yenmez, A. A., Özpinar, Ý., \& Gökçe, S. (2017). Use of webquests in mathematics instruction: Academic achievement, teacher and student opinions. Universal Journal of Educational Research, 5(9), 1554-1570. https://doi.org/10.13189/ ujer.2017.050913

Yu, R., \& Singh, K. (2018). Teacher support, instructional practices, student motivation, and mathematics achievement in high school. The Journal of Educational Research, 111(1), 81-94. h t tp s: / / doi.org/10.1080/ 00220671.2016 .1204260

Zengin, Y., Furkan, H., \& Kutluca, T. (2012). The effect of dynamic mathematics software geogebra on student achievement in teaching of trigonometry. Procedia Social and Behavioral Sciences, 31, 183187. https://doi.org/10.1016/ j.sbspro.2011.12.038

Zulnaidi, H., \& Zakaria, E. (2012). The effect of using GeoGebra on conceptual and procedural knowledge of high school mathematics students. Asian Social Science, 8(11). https://doi.org/ $10.5539 /$ ass.v8n $11 \mathrm{p} 102$

Received 22 December 2020 Revised 16 April 2021 Accepted 31 July 2021 
